\title{
Including the normal to shear stresses ratio in fatigue life estimation for cyclic loadings
}

\author{
Marta Kurek $^{1}$ \\ ${ }^{1}$ Department of Mechanics and Machine Design, Opole University of Technology, 5 Mikołajczyka \\ Street, 45-271 Opole, Poland
}

\begin{abstract}
The paper presents the estimation of the fatigue life under multiaxial cyclic loading of two construction materials. The main aim of this paper is to present a new method which allows evaluation of fatigue life during the design and construction phase of machine elements. In paper three well known multiaxial fatigue criteria based on the critical plane approach verified. This paper contains a proposition to define a new way of determining an orientation angle of the critical plane. The comparison between experimental and theoretical results varying the critical plane orientation appears to be satisfactory.
\end{abstract}

\section{Introduction}

The practical aspect of more than 170 years' history of fatigue phenomenon research is the proposed methods of estimating the fatigue life of materials or structures. Their main objective is to predict the time of the reliable and safe operation of a machine or device already at the construction or design stage. The structural elements of machines and devices are subject to loads varied in terms of their properties. These are generally multi-axis load states. The complex nature of the occurring fatigue processes resulted in a large group of fatigue criteria constituting the basic tool in the estimation algorithm for fatigue life. These hypotheses reduce the spatial tension state to the equivalent single-axis tension state. The multi-axial fatigue criteria arising from the above hypotheses may be divided due to the physical nature of a parameter deciding on destruction into: stress, strain and energy (stressstrain). Stress criteria constitute one of the largest groups of fatigue criteria taken from the classic theories of damage. During their adaptation, a set of criteria was established based on the critical plain concept. This group of criteria will be the subject of considerations in this study because criteria based on tensions are preferred by engineers when calculating the fatigue life of structural elements.

The main aim of this paper is present a new method which allows evaluation of fatigue life during the design and construction phase of machine elements.

In paper three well known multiaxial fatigue criteria based on the critical plane approach are verified: Carpinteri-Spagnoli criterion [1], modified C-S criterion [2] and one proposed by the author [3]. The proposed model has been verified based on the results of own and literature experimental studies, obtaining satisfying results. 


\section{Fatigue strength evaluation}

Generally, the estimation of fatigue strength consists of several stages (Fig.1). The first step includes measurement, generation or calculation of the stress tensor components according to the following equations, in the case of biaxial fatigue (for example, cyclic bending and torsion):

$$
\begin{gathered}
\sigma_{x x}(t)=\sigma_{a} \sin (\omega t) \\
\tau_{x y}(t)=\tau_{a} \sin (\omega t-\varphi)
\end{gathered}
$$

where $\sigma_{x x}(t)$ refers to stress induced by bending, and $\tau_{x y}(t)$ refers to torsion-induced stress. Further: $\sigma_{a}$ - amplitude of normal stress induced by bending; $\tau_{a}$ - amplitude of shear stress induced by torsion; $\omega$ - pulsation; $\varphi$ - phase shift; $t$ - time. The input data within the model presented are tension values. This study uses normal tension amplitudes $\sigma_{\mathrm{a}}$ for calculations, from bending and the shear stress amplitude $\tau_{\mathrm{a}}$ from torsion.

1. Determination of stress tensor components

2. Determination of the critical plane orientation, $\alpha$

3. Calculation of the equivalent course, $\sigma_{\text {eq,a }}$

4. Calculation of fatigue life, $\mathrm{N}_{\mathrm{cal}}$

Fig. 1. A scheme for estimating fatigue life under cyclic loading

The critical plain concept is strictly related to the reduction of the multi-axis state to the single-axis equivalent [4].

The course of normal stress turned at angle $\alpha$ with respect to $\sigma_{x x}$ is given by the formula

$$
\sigma_{\eta}(t)=\sigma_{x x} \cos ^{2} \alpha+\tau_{x y}(t) \sin 2 \alpha
$$

Whereas, the course of tangential stress was written as:

$$
\tau_{\eta S}(t)=-\frac{1}{2} \sigma_{x x}(t) \sin 2 \alpha+\tau_{x, y}(t) \cos 2 \alpha
$$




$$
\alpha=\alpha_{\eta}+\beta
$$

where: $\alpha_{\eta}$ - maximum angle determined by normal stresses

In this study, three expressions determining the angle $\beta$ were used for considerations. First is the angle proposed by Carpinteri $\left(\beta_{c}\right)$, which is defined in relation to the direction determined by the maximum in the normal direction [1]

$$
\beta_{C}=\frac{3}{2}\left[1-\left(\frac{1}{B_{2}}\right)^{2}\right] 45^{\circ},
$$

where $\mathrm{B}_{2}$ is the fatigue limit ratio expressed by means of the formula

$$
B_{2}=\frac{\sigma_{a f}}{\tau_{a f}}
$$

It has been assumed that the ratio of the of fatigue limits corresponds to the stresses for $N f=$ $2,000,000$ cycles. The second expression $\left(\beta_{\text {mod }}\right)$ is a modified form of equation (6), namely the calculation of the critical plane orientation angle the ratio of normal to shear stress amplitude is used instead of the fatigue limits.

$$
\beta_{\text {mod }}=\frac{3}{2}\left[1-\left(\frac{\tau_{a}}{\sigma_{a}}\right)^{2}\right] 45^{\circ} .
$$

The third expression (see Eq. 9) is a new expression for angle $\beta$, which is used for determining the critical plain orientation angle. The pre-assumptions concerned the following:

- the consideration of the ratio value of normal to shear stress amplitude in the function of cycle number instead of the ratio of fatigue limits;

- including values lower than 1 and higher than $\sqrt{3}$;

- the use of ctg function, which, in the first calculations, was almost a perfect match for the analysed data.

$$
\operatorname{ctg}\left(4 \beta_{A}\right)=22,5^{\circ}\left[\frac{1+\sqrt{3}}{2}-\frac{\sigma_{a}}{\tau_{a}}\left(N_{f}\right)\right] \operatorname{dla} 0^{\circ} \leq \beta_{A} \leq 45^{\circ}
$$

The reduction of the multi-axis load state to the single-axis equivalent state is another essential step in estimating the fatigue life. The calculations involved the modified criterion in the plain of maximum normal and shear stresses. This is a new criterion based on the assumptions considering pure load states.

$$
\sigma_{e q, a}=B \tau_{\eta s, a}+K \sigma_{\eta, a},
$$

where parameters $\mathrm{B}$ and $\mathrm{K}$ are as follows [5]:

$$
B=\frac{B_{2}-\frac{\sin \left(90^{\circ}+2 \beta\right)}{\cos ^{2} \beta}}{\frac{\sin 2 \beta \sin \left(90^{\circ}+2 \beta\right)}{2 \cos ^{2} \beta}+\cos \left(90^{\circ}+2 \beta\right)},
$$




$$
K=\frac{2+B \sin 2 \beta}{2 \cos ^{2} \beta}=2-\frac{\sigma_{a f}}{\tau_{a f}} .
$$

Fatigue life was calculated with the use of the Wöhler's fatigue characteristic in accordance with ASTM [6] and the expression

$$
\log N_{\mathrm{f}}=A-m \log \sigma_{\mathrm{aeq}}
$$

\section{Experimental research and analysis of literature data}

This publication presents a description of experimental studies along with an analysis of their results for $16 \mathrm{Mo} 3$ steel. Experimental tests for simple load states, as well as for a combination of proportional bending and torsion, were carried out on the MZGS-100 fatigue machine by the Achtelik project (Fig. 2). The MZGS-100 test stand consists of a drive system, head, loading system and control-measurement system. The parameter controlled during tests was the total moment course Mc loading the sample. The required sample load was obtained through the proper balancing of rotating discs and setting a lever turning angle.

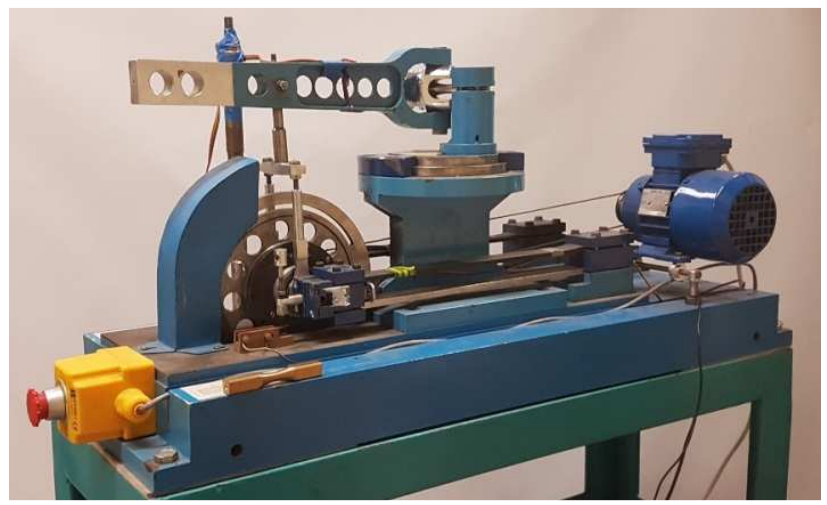

Fig. 2. MZGS-100 fatigue machine

Steel $16 \mathrm{Mo} 3$ is boiler steel, these are creep-resistance grades, maintaining good ductility and malleability - in hot and in cold conditions. They are perfect in treatment and they guarantee welding simplicity with the use of conventional methods and welding materials. Owing to the increased presence of molybdenum (Mo), they are applied in the conditions of higher temperature. Whereas, the presence of chrome $(\mathrm{Cr})$ makes steel resistant to corrosion in the environment of water steam. The chemical composition of steel $16 \mathrm{Mo} 3$ is presented in Table 1 , and strength properties are shown in Table 2

Table 1. Chemical composition of steel 16Mo3 (residue Fe)

\begin{tabular}{|l|l|l|l|l|l|l|l|l|l|}
\hline C & Si & Mn & P & S & Cr & Mo & Ni & Cu & N \\
\hline $0,12-$ & $<0,35$ & $0,4-$ & $<0,025$ & $<0,010$ & $<0,3$ & $0,25-$ & $<0,3$ & $<0,3$ & $<0,012$ \\
0,20 & & 0,9 & & & & 0,35 & & & \\
\hline
\end{tabular}


Table 2. Strength properties of steel $16 \mathrm{Mo} 3$

\begin{tabular}{|l|l|l|l|}
\hline $\mathrm{Rp} 0,2, \mathrm{MPa}$ & $\mathrm{Rm}, \mathrm{MPa}$ & $\mathrm{A}_{5}, \%$ & $\mathrm{v}$ \\
\hline 335 & 481 & 24 & 0.30 \\
\hline
\end{tabular}

Smooth samples with the round "diabolo" type section (Fig. 3) without a geometrical notch were used in fatigue tests.

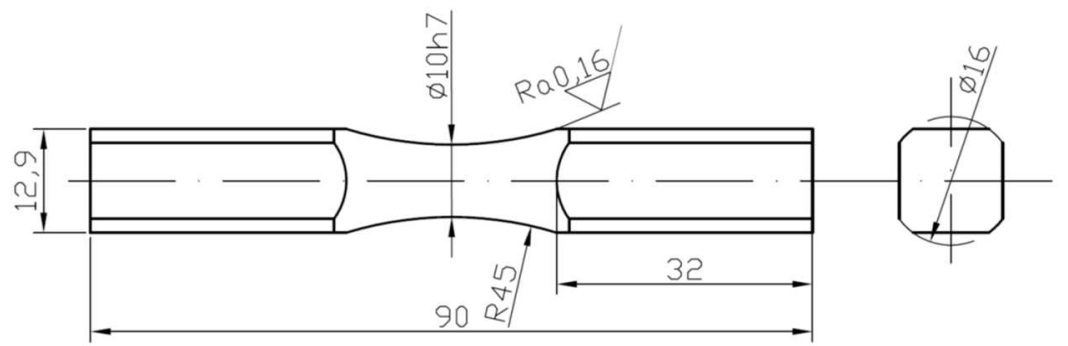

Fig. 3. The geometry of samples used in tests

The range of fatigue tests included: bending $\tau_{\mathrm{a}}=0$, torsion $\sigma_{\mathrm{a}}=0$, bending with torsion $\tau_{\mathrm{a}}=$ $0.5 \sigma_{\mathrm{a}}$. The results of fatigue tests using the $\mathrm{S}-\mathrm{N}$ fatigue diagram in a double logarithmic system was presented in fig. 4 and 5.

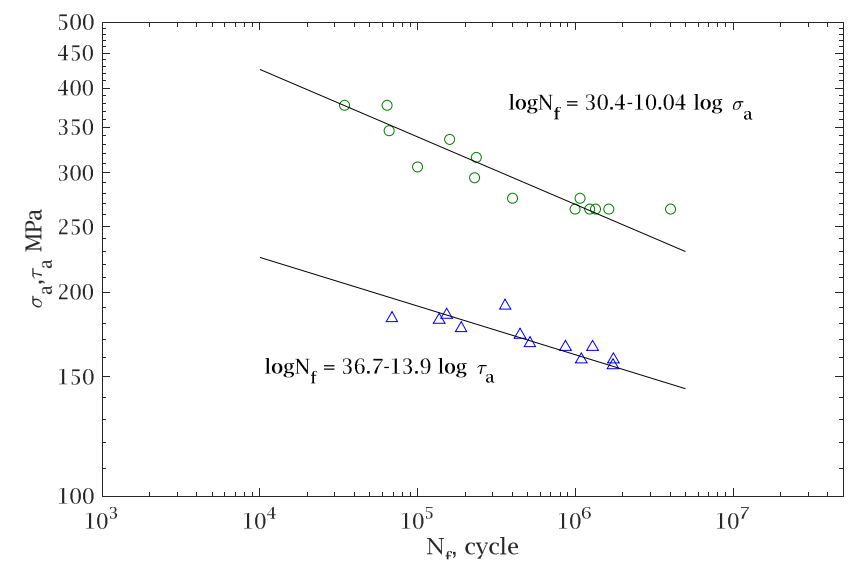

Fig. 4. Fatigue graph for pendulum bending and double-sided torsion for steel $16 \mathrm{Mo3}$ 


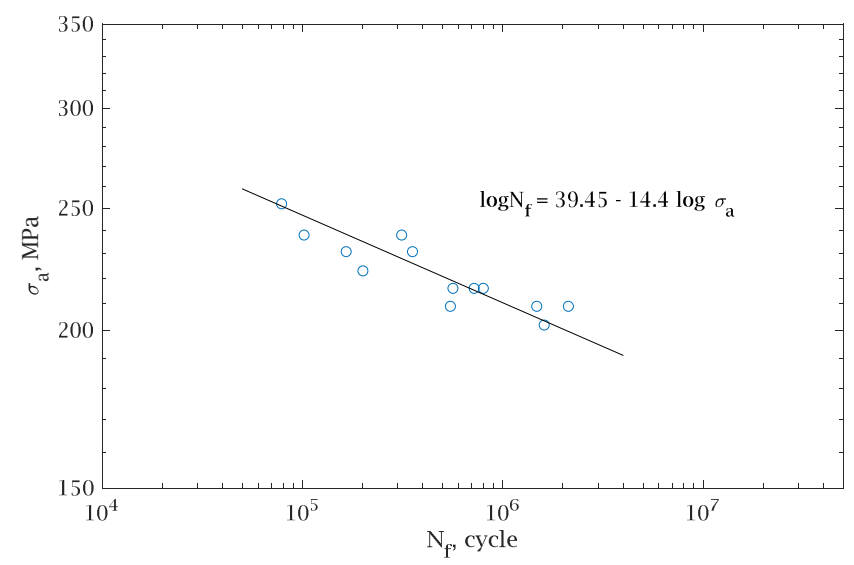

Fig. 5. Fatigue graph for combined bending and torsion $\tau_{\mathrm{a}}=0.5 \sigma_{\mathrm{a}}$ for steel $16 \mathrm{Mo} 3$

The second material analyzed in this work is GTS45 cast iron, the description and results of the research were taken from the ref. [7]. Cast iron is a casting alloy of iron with carbon and other components containing from 2 to $3.6 \%$ of carbon in the form of iron carbide or graphite. Cast irons, GTS45 was selected for the analysis of fatigue tests results. The geometries of samples are presented in Fig. 6. Chemical composition is presented in Table 3, and strength properties are specified in Table 4. Regression equation coefficients according to ASTM norm for the respective load variants are presented in Table 5.

Table 3. Chemical composition of iron GTS45 (residue Fe)

\begin{tabular}{|l|l|l|l|l|}
\hline C & Si & Mn & S & Cr \\
\hline 2,66 & 1,37 & 0,62 & 0,17 & 0,07 \\
\hline
\end{tabular}

Table 4. Strength properties of iron GTS45

\begin{tabular}{|l|l|l|l|}
\hline $\mathrm{R}_{\mathrm{e}}, \mathrm{MPa}$ & $\mathrm{Rm}, \mathrm{MPa}$ & $\mathrm{E}, \mathrm{GPa}$ & $\mathrm{A} 5, \%$ \\
\hline 310 & 469 & 167 & 9,4 \\
\hline
\end{tabular}

Table 5. Coefficients of regression equations for the analysed material

\begin{tabular}{|c|c|c|c|}
\hline \multicolumn{2}{|c|}{ Tension-compression } & \multicolumn{2}{|c|}{ Torsion } \\
\hline $\mathrm{A}_{\sigma}$ & $\mathrm{m}_{\sigma}$ & $\mathrm{A}_{\tau}$ & $\mathrm{m}_{\tau}$ \\
\hline 53 & $-19,4$ & 35,3 & $-12,8$ \\
\hline
\end{tabular}




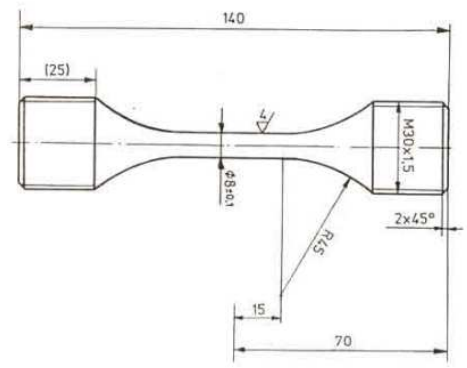

Fig. 6. The geometry of samples used in tests [7]

\section{Verification of the proposed multiaxial criterion}

The fatigue life was calculated in order to verify the conformity of the experimental data with calculations using the new form of expression for the $\beta$ angle. The purpose of the experiment analysis is to find out the effectiveness of the proposed method of fatigue life estimation in the conditions of the applied loads during bending and torsion. The fatigue calculation results may be presented in the graphic form by various means. The graph which is used most frequently, is the graph presenting the comparison of the calculated fatigue life with the experimental fatigue life and this approach has been applied in this paper. The comparison was carried out for the combined bending and torsion. The analysis for bending and torsion was skipped because the estimated fatigue life values were the same as for each analysed angle.

The calculated and experimental fatigue life values are compared in Fig. 6-7 for the analysed materials. Each graph includes also the values of angles $\beta$ calculated on the basis of three dependencies (6,8 and 9)

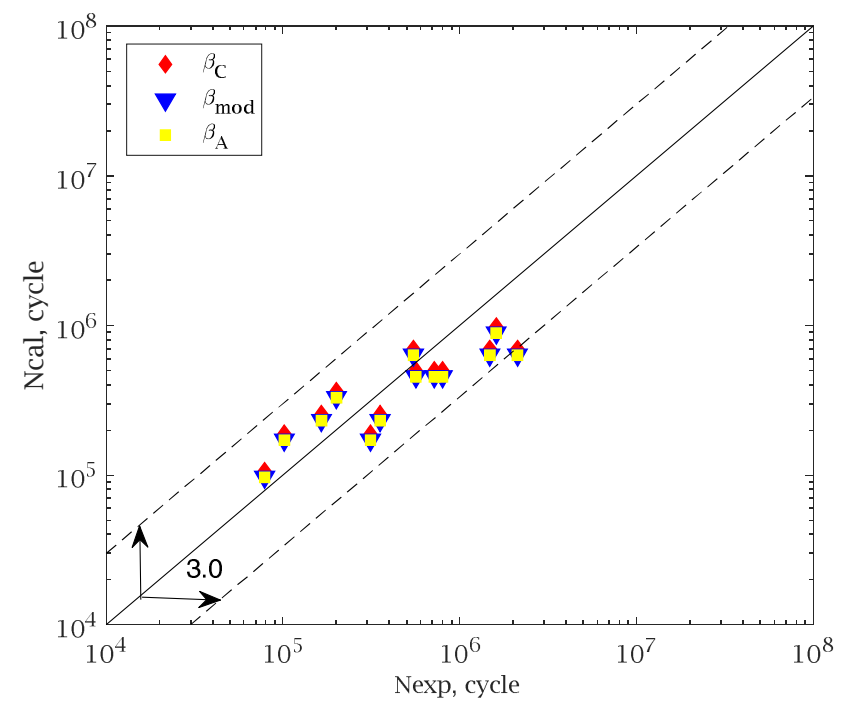


Fig. 6. Experimental fatigue life vs predicted fatigue life for experimental data of $16 \mathrm{Mo} 3$ steel by applying: $\beta_{\mathrm{C}} ; \beta_{\text {mod }}$ and $\beta_{\mathrm{A}}$

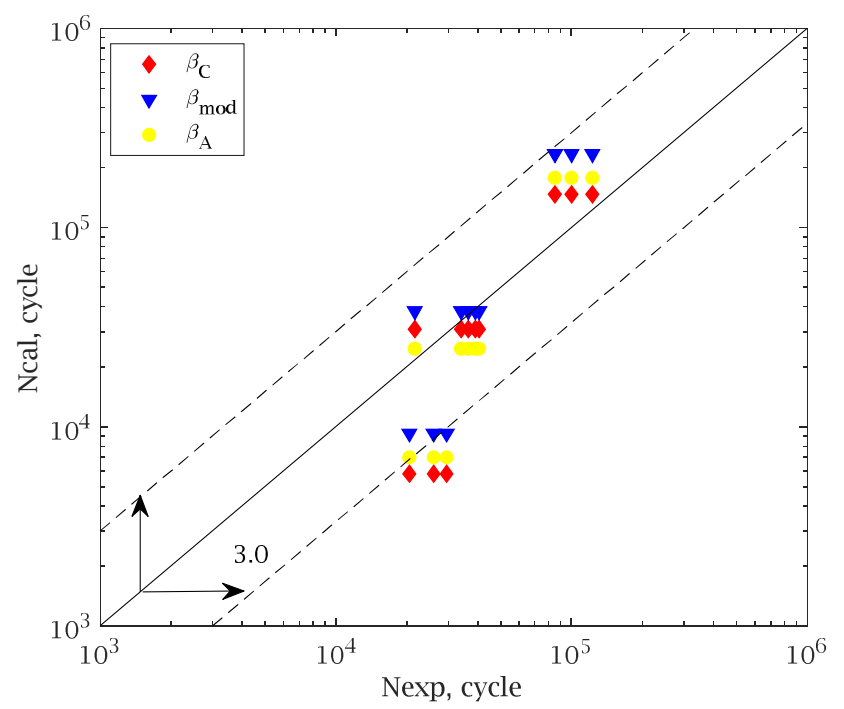

Fig. 7. Experimental fatigue life vs predicted fatigue life for experimental data of GTS45 iron by applying: $\beta_{\mathrm{C}} ; \beta_{\bmod }$ and $\beta_{\mathrm{A}}$

\section{Summary}

On the basis of the literature overview, the analysis of the experiment results and literature results as well as the performed calculations, the following conclusions were drawn:

1. A new proposal of angle $\beta$ made by the author is based on the ratio of normal and shear stresses and it allows a wider range of that ratio than $\langle 1 ; \sqrt{3}\rangle$. It is crucial with the analysis of materials with non-perpendicular characteristics.

2. Carpinteri's proposal was modified by the author through the replacement of the ratio of fatigue life limits with the value of the ratio of normal to shear stress for a given number of cycles.

3. After the analysis of the results of comparing the calculated fatigue life values with the experimental ones, it may be stated that the proposed algorithm of estimating fatigue life provides satisfactory outcomes for multi-axis cyclic loads what is shown by the average dispersion equalling 3.00 .

4. In the future, further analysis of the proposed model for subsequent construction materials will be carried out

Acknowledgement: The authors gratefully acknowledge the support by the Polish National Science Centre (No. 2016/21/D/ST8/02007) 


\section{References}

1. A. Carpinteri, A. Spagnoli, Multiaxial high-cycle fatigue criterion for hard metals. International Journal of Fatigue, 23, p.135-145 (2001)

2. A. Carpinteri, M. Kurek, T. Łagoda., S. Vantadori, Estimation of fatigue life under multiaxial loading by varying the critical plane orientation, International Journal of Fatigue, 100, p. 512-520 (2017)

3. M. Kurek, Verification of new model for determining the critical plane orientation angle, E3S Web of Conferences, 19, UNSP 03017, (2017)

4. M. Kurek, T. Łagoda, Determination of the critical plane orientation depending on the fatigue curves for bending and torsion, Frattura ed Integrita Strutturale, 41, p.24-30 (2017)

5. A. Carpinteri, S. Vantadori, T. Łagoda, A. Karolczuk, M. Kurek, C. Ronchei, Fatigue assessment of metallic components under uniaxial and multiaxial variable amplitude loading, Fatigue \& Fracture of Engineering Materials \& Structures 41, p. 1306-1317, (2018)

6. ASTM E1049-85, Standard practices for cycle counting in fatigue analysis. The American Society for Testing and Materials, West Conshohocken, PA, (2003)

7. A. Muller, Zum Festigkeitsverhalten von mehrachsig stochastisch beanspruchten Gus seisen mit Kugelgraphit und Tempergu. Fraunhofer-Institut fur Betriebsfestigkeit, Darmstadt, (1994) 